International Journal of Heritage, Tourism and Hospitality Vol. (12), No. (3/2)

Special issue on papers of the $11^{\text {th }}$ ICTH (2018) organized by Faculty of Tourism and Hotels,

Fayoum University

\begin{abstract}
The Negation of the so-called 'the Second Tense' in Middle Egyptian'
Amany Abd El- Hameed ${ }^{2}$

Faculty of Archaeology, Fayoum University.

\section{Introduction}

In linguistic dictionaries (English, French, German, Arabic, etc..), there is no existence for the second tense, this term was established by Polotsky (Polotsky, H.J., Études de syntaxe copte, Publications de la Société d' Archéologie Copte, Le Caire, 1944), according to his theory, the second tense is a nominalized verb form, and usually used as a noun clause; referring to the subject before the focused adverbial phrase. On one hand, the second tense form is a special case of 'relative forms' use. Therefore, on the other hand, it is actually not a tense, but rather use of grammar element. It is simple, one can say the second tense is equal to (Restriction form by innama) in Arabic. As for Arabic and Ancient Egyptian are relating to the same Language family 'Afro-asiatic family', one expected that they at least have more or less the same main linguistic terms. In the article, I try to give a general idea about the meaning of the so-called 'Second Tense', and its important usages. Moreover, the article focuses on the negation of the so-called "Second Tense."

The point of departure of the article was an investigation of the negative particles according to their appearance in various sentence patterns, I found that some particles are limited to negate the adverbial adjunct of the sentence, whereas others negate the verb itself.
\end{abstract}

\title{
Main Research Objectives
}

The study tries to

illustrate the methods of the negation of the second tense in Middle Egyptian.

Clarify whether the second tense form verbal or non-verbal form, this can be seen through the study of the particles of negative used in the same formula and this has been shown through the literary or the religious texts in the middle age.

study the role of each of the negative particles used to negate the second tense forms and clarify whether they negate the main verb or negate another event in the sentence.

\section{Method of Research}

The study uses the comparative analytical descriptive method, The study is based on the analysis of Middle Egyptian texts, clarifying the negative particle which was used, explaining its role in the sentence, and elaborating the negative part of the sentence. The negative structure of the emphatic form/Second Tense

In Middle Egyptian there are three different ways to negate the so-called Second Tense forms

Negation by $\mathbf{n}$...is

If the stressed adverbial adjunct is negated the double-part construction " $n$...is" is used. "Negation of the Rheme, negative sentence with an affirmative verb."

\footnotetext{
${ }^{1}$ This article is apart of my MA thesis, "The Second Tense in the Middle Egyptian”, which is registered at Egyptology department, Faculty of Archaeology, Fayoum university, under supervision of Dr. Maher A. Eissa\& Prof. Dr. Ahmed Al-Ansary.

${ }^{2}$ A special debt is owed to Dr. Maher A. Eissa, for his unending support, invaluable insights, guidance throughout various stages of my research, and above all his patience in overseeing every stage of this endeavor with invaluable suggestions, regarding the general direction and content of the research, I owe him many thanks for his support. I express my sincere gratitude to him and to his immense practical help.
} 
International Journal of Heritage, Tourism and Hospitality Vol. (12), No. (3/2)

Special issue on papers of the $11^{\text {th }}$ ICTH (2018) organized by Faculty of Tourism and Hotels,

Fayoum University

\section{Negation by tm}

If the verb itself is negated, the negative verb tm will be followed by a negative complement.

\section{Negation by $n$-is}

There is another way to negate the adverbial adjunct of the so-called Second Tense form: by using $\mathrm{n}$-is which occurs if there are two or more adverbials, but one is affirmative and the other is negated. The negated adverbial is preceded by $\mathrm{n}$ is.

Keywords Adverbial adjunct - Middle Egyptian - Rheme - Second Tense - Standard Theory.

\section{Meaning}

"The Second Tenses are chosen when the speaker focuses on another part of the sentence, not on the verbal action; it is used to 'nominalize the verb itself' and emphasize the adverbial adjunct when this adverbial adjunct is a logical predicate."3

According to Browne, ${ }^{4}$ to nominalize the verb itself, it should be put into the so-called "Second Tense form."

The Second Tense is a form whose basic significance is adverbial rather than temporal; it is used to express ideas that must be translated as subordinate, as well as the main clause. ${ }^{5}$

The negative structure of the emphatic form/Second Tense

In Middle Egyptian, there are three different ways to negate the emphatic forms

Negation by n...is $\lfloor$.

If the stressed adverbial adjunct is negated the double-part construction $n \simeq \sim \ldots$ is $\sim \mid l$ is used. ${ }^{6}$ "Negation of the Rheme, negative sentence with an affirmative verb."7

$\underset{n}{n}\lfloor$...is and $\mathrm{sDm} \cdot \mathrm{n}=\mathrm{f}^{8}$ in these cases, the sentence is not a regular verbal sentence, but rather is an emphatic sentence with stressed adverbial adjunct. ${ }^{9}$

The existence of the negation $\_$n...is $4 \|$ as a negation of emphatic sentences prove the existence of Second Tense with their function as a subject to emphasized adverbial adjuncts. ${ }^{10}$ The negative n...is $4 \mid$ is the ancestor of the late Egyptian bn m ...iwnA the Coptic negative n....an. ${ }^{11}$

Ex (1):

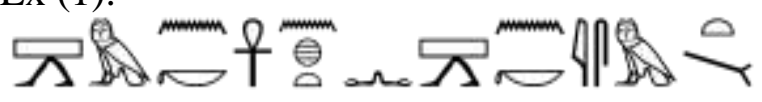

${ }^{3}$ Gardiner (1947:95-6); Widmer (1999:166).

${ }^{4}$ Browne (1996-1).

${ }^{5}$ Bowling (1962:15).

${ }^{6}$ Gilula (1970:209) ; Gilula (1972:59)

${ }^{7}$ Allen(2014:429).

${ }^{8}$ Allen (2017:159-60).

${ }^{9}$ Gilula (1968: II,IV,80); Gilula (1970:208);Collier (2016:159).

${ }^{10}$ Gilula(1968: VI,80); Gilula(1970:209).

${ }^{11}$ Gilula(1970:210); Winand (1997:223). 
International Journal of Heritage, Tourism and Hospitality Vol. (12), No. (3/2) Special issue on papers of the $11^{\text {th }}$ ICTH (2018) organized by Faculty of Tourism and Hotels, Fayoum University

$\check{s} m . n=k \quad n h . t(i) n i \grave{s} m . n=k$ is $m(w) t .(t i)^{12}$

It is alive that you have gone away, it is not dead that you have gone away. ${ }^{13}$

The particle is signals that the sDm. $n=f$ clause is subordinate to the negation, rather than just the verb form itself. ${ }^{14}$

Ex (2):

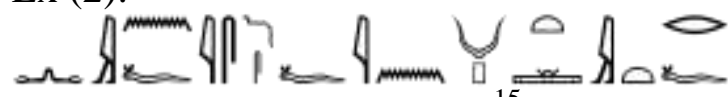

$n$ il. $n=f$ is $\underline{d} s=f$ in wpt ilt $r=f^{15}$

He came by himself, not by the message which came for him. ${ }^{16}$

Ex (3):

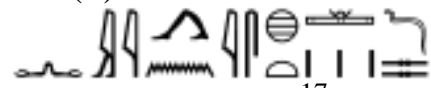

$n \hat{i l}=n$ is $h w t \underline{d} \mathbf{d}=\mathbf{s}^{17}$

Things came not by themselves. ${ }^{18}$

Ex (4):

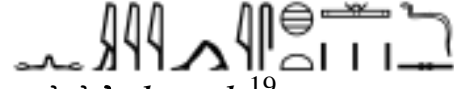

$n$ iyli is $h w t \underline{d} s^{19}$

Things are coming not by themselves. ${ }^{20}$

The expression Ds + suffix pronoun is not simply a nominal sentence, it is adverbial phrase. ${ }^{21}$

Ex (5):

几

$n$ ir $=k$ is šmt shdt $t^{22}$

You are walking, not downwards.

Ex (6):

几

$n \check{s} m=. \grave{l}$ is $s h d h d y^{23}$

I am walking, not upside down.

Ex (7):

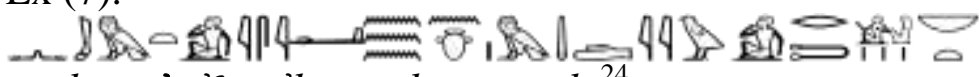

$n$ whm=t is ic $n$ ib $m$ mdyw rmt $n b t^{24}$

Washing of the heart should not be repeated in the speech of any people. ${ }^{25}$

The existence of "is" shows that the negative particle" $n$ " doesn't apply to the verb itself, but to the whole sentence.

The construction $n$...is functions as a mark of an emphatic sentence. ${ }^{26}$

\footnotetext{
${ }^{12}$ CT I, 187 e.

${ }^{13}$ Allen (2014:430).

${ }^{14}$ Allen (2017:160).

${ }^{15}$ CT VI, 401, m-o.

${ }^{16}$ Gilula (1968:80).

${ }^{17}$ Kagmni\&Ptah.L2 181.

${ }^{18}$ Gilula (1968:82).

${ }^{19}$ Kagmni\&Ptah.181.

${ }^{20}$ Gilula (1968:82).

${ }^{21}$ Meltzer (1975:33-4).

${ }^{22}$ CT I, 59e-60b.

${ }^{23}$ CT VII ,233

${ }^{24}$ Kagmni\&Ptah, 152.

${ }^{25}$ Allen (2015:180).
} 


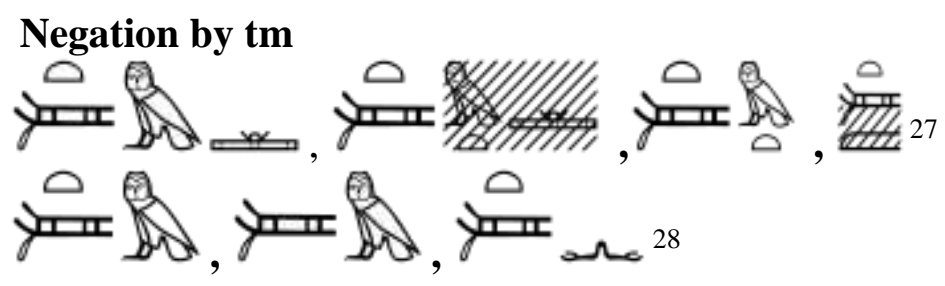

If the verb itself is negated the negative verb tm is used ${ }^{29}$ followed by a negative complement. ${ }^{30}$ $\mathrm{tm}$ is a negative verb ${ }^{31}$ which is the negation of the nominal forms of the verb. ${ }^{32}$ It occurs before the "that-form" or Second Tense $\mathrm{sDm}=\mathrm{f}, \mathrm{sDm} . \mathrm{n}=\mathrm{f}$ and $\mathrm{sDmw}=\mathrm{f},{ }^{33}$ in which case the action is negated. ${ }^{34}$ Polotsky's footnote ${ }^{35}$ :

"Simple proof is available if the view is accepted that all forms of the suffix conjugation which are negated by tm are by this very fact shown to be 'Emphatic.'"

$t m=f s \underline{d} m$ form

Ex (1):

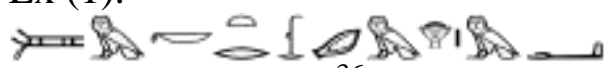

tm $=k$ tr $s \underline{d m} h r m-e^{36}$

Why don't you listen? ${ }^{37}$

Ex (2):

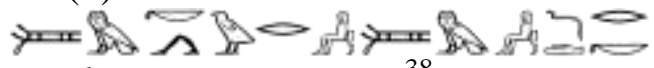

$t m=k i w \quad r=i \quad t m=i d d r=k^{38}$

You don't come against me, I won't speak against you. ${ }^{39}$

Ex (3)

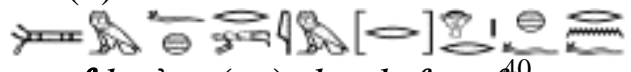

$t m=f h r$ im $(r) h r \quad r h=f r n=f^{40}$

He doesn't fall on his face there, because he knows his name. ${ }^{41}$

Ex (4):

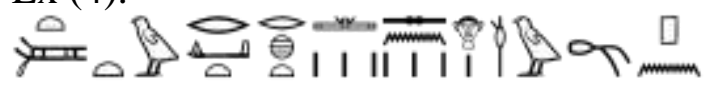

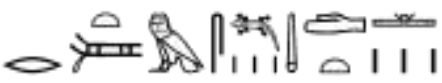

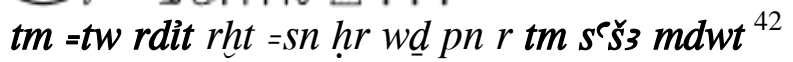

${ }^{26}$ Allen (2014:431).

${ }^{27}$ Cassonent (2000:114).

${ }^{28} \mathrm{~Wb} \mathrm{~V}, 301-2$.

${ }^{29}$ Uljas (2007:210).

${ }^{30}$ Englund (1995:68); Uljas (2007:210); Allen (2014:430).

${ }^{31}$ Englund (1995:68).

${ }^{32}$ Cassonent (2000:113); Jenni (2010:242)

${ }^{33}$ Gilula (1970:209); Gilula (1974:249); Englund (1995:68); Cassonent (2000:114).

${ }^{34}$ Gilula (1970:209); Allen (2014:430).

${ }^{35}$ Polotsky (1957:109, n.3).

${ }^{36}$ Peas.B1 211.

${ }^{37}$ Allen (2014:430).

${ }^{38} \mathrm{CT} \mathrm{V}, 326 \mathrm{~h}$.

${ }^{39}$ Allen (2014:430).

${ }^{40}$ CT VII 11 o.

${ }^{41}$ Allen (2014:430).

${ }^{42}$ Urk.IV 693, 12-13. 
International Journal of Heritage, Tourism and Hospitality Vol. (12), No. (3/2)

Special issue on papers of the $11^{\text {th }}$ ICTH (2018) organized by Faculty of Tourism and Hotels,

Fayoum University

It is in order not to multiply the words that one has not put a number of them on this stela. ${ }^{43}$

Ex (5):

A $\triangle$ H

且口等

$m k$ z $i b=k \quad t m=f d h i \quad m$ gr szw hnd $=k^{44}$

Do not be arrogant of heart, and it won't be humbled; don't be inactive, but beware when you tread. $^{45}$

Ex (6)

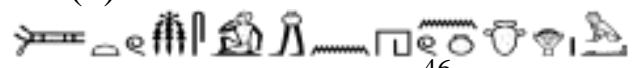

tm.tw ms in hnw hr m- ${ }^{\mathrm{C} 6}$

Why does not one fetch the jars then $?^{47}$

In the first and last examples; tm negates the verbs (sDm, ms) in the sentence with interrogative rheme $\mathrm{Hr}$ m-a .

The second example is a balanced sentence ( $\mathrm{tm}=\mathrm{k}$ iw, $\mathrm{tm}=\mathrm{i} \mathrm{Dd})$ : two emphatic forms with two verbs negated by tm and followed by adverbial adjuncts $(\mathrm{r}=\mathrm{i}, \mathrm{r}=\mathrm{k})$.

Third, fourth and fifth examples are examples of three negative emphatic sentences $(\mathrm{tm}=\mathrm{f} \mathrm{xr}, \mathrm{tm}$ .tw rdit, tm=f dHi) with affirmative adjuncts ( $\mathrm{r} \mathrm{Hr} \mathrm{rx=f,} \mathrm{Hr} \mathrm{wD} \mathrm{pn,} \mathrm{m} \mathrm{gr} \mathrm{sAw).}$

Note: In these examples, the verb itself is negated, not the adverbial adjunct.

tm . $\mathrm{n}=\mathrm{f}$ sDm sentence:

The occurrence of $\mathrm{tm} . n=f s \underline{d} m$ proves the existence of "emphatic" $s \underline{d} m . n=f^{48}$

The existence of the emphatic sDm.n=f has been proved by the existence of the negative $n$ sDm.n $=$ f is. ${ }^{49} \mathbf{t m} . \mathbf{n}=\mathbf{f} \mathbf{s D m}$ is emphatic or nominal sDm.n.f, ${ }^{50}$ and the occurrence of $\mathbf{t m} . \mathbf{n}=\mathbf{f} \mathbf{s D m}$ will complete the arguments of the existence of the Second Tense, and will complete the parts of the negative structure of the Second Tense. ${ }^{51}$

According to Gilula ${ }^{52}$, In Middle Egyptian, there is an important example of $\mathrm{tm} . \mathrm{n}=\mathrm{f}$ sDm attested by the Coffin Texts, CT VI, 414j-k (T6C).

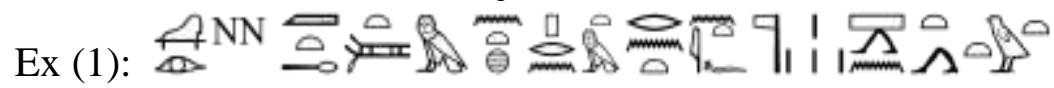

Wsir $N$ met hrw tm.n=t hpr. $n=t \quad m$ rn.t $n$ it ntrw šm $. n=t i w t=t$

Osiris N justified, it is into your name of "father of the Gods" that you didn't change. It is in order to come back that you have departed. ${ }^{53}$

Ex (2):

nn hisst tm.n=k hnd $=s^{54}$

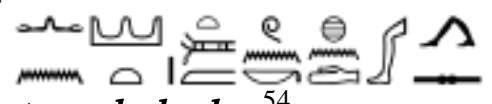

There is no foreign country, which you have not trodden yet. ${ }^{55}$

\footnotetext{
${ }^{43}$ Hoch (1997:208).

${ }^{44}$ Kagmni\&Ptahhotep 374-5.

${ }^{45}$ Allen (2015:201).

${ }^{46}$ West.11.21-2.

${ }^{47}$ Englund (1995:68).

${ }^{48}$ Polotsky (1957:109,n.3) ;Gilula (1974:249).

${ }^{49}$ Gilula (1970:209); Gilula (1972:56-9);Gilula (1974:249).

${ }^{50}$ Osman (2013:38).

${ }^{51}$ Gilula (1974:249)

${ }^{52}$ Gilula(1974:249).

${ }^{53}$ Gilula (1974:249).

${ }^{54}$ KRI II, 356(1).
} 
International Journal of Heritage, Tourism and Hospitality Vol. (12), No. (3/2)

Special issue on papers of the $11^{\text {th }}$ ICTH (2018) organized by Faculty of Tourism and Hotels,

Fayoum University

tm. $n=k$ hnd Emphatic sDm.n=f form. This form is NIMS after IMS nn xAst, a negated nominal sentence. ${ }^{56}$

There is only one example negated by tm to negate the verb, attested in P. Louvre 3230 b, 7-8, JEA 12(1926), pl. XVII). ${ }^{57}$

Ex (3):

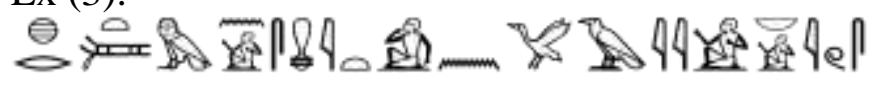

Dी०

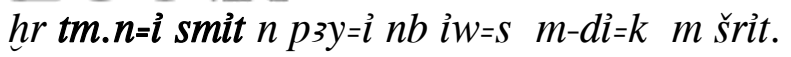

And it's because she was with you as a girl that I have made no report to my lord. ${ }^{58}$

According to Gardiner, ${ }^{59}$ when a double negative is used in the form of emphatic assertion, tm is translated as "fail." 60

Ex (1):

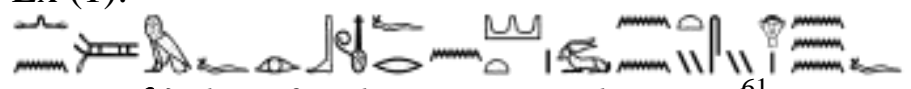

$n n t m=f$ ir bw nfr $n$ hist wnnty. sy $h r m w=f^{61}$

He will not fail to do well to the land that will be loyal to him. ${ }^{62}$

Ex (2):

Stom

st $m w$ n $t m . n=f^{e} n w^{63}$

The pourer of water, he never fails to return. ${ }^{64}$

$n n t m=f$ in the first example is prospective, $\mathrm{nn}$ is a negative particle and $\mathrm{tm}$ is a negative verb; $\mathrm{nn}$ negates tm.

$n$ tm. $n=f{ }^{e} n w$ in the second example is ' $t m . n=f$ sDm sentence "emphatic," with ' $n w$ negated by $t m$, and $n t m . n=f{ }^{`} n \boldsymbol{w}$ negated by $n$.

Negation by $n$-is

There is another way to negate the adverbial adjunct of the emphatic sentence/Second Tense form: by using $n$-is which occurs if there are two or more adverbials, but one is affirmative and the other is negated. The negated adverbial is preceded by $n$ is. ${ }^{65}$

Ex (1):

Petrie ,Dendereh,pl.x. ${ }^{66}$

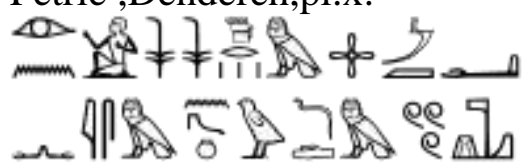

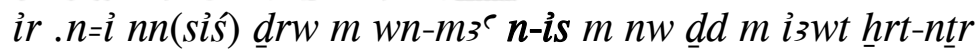

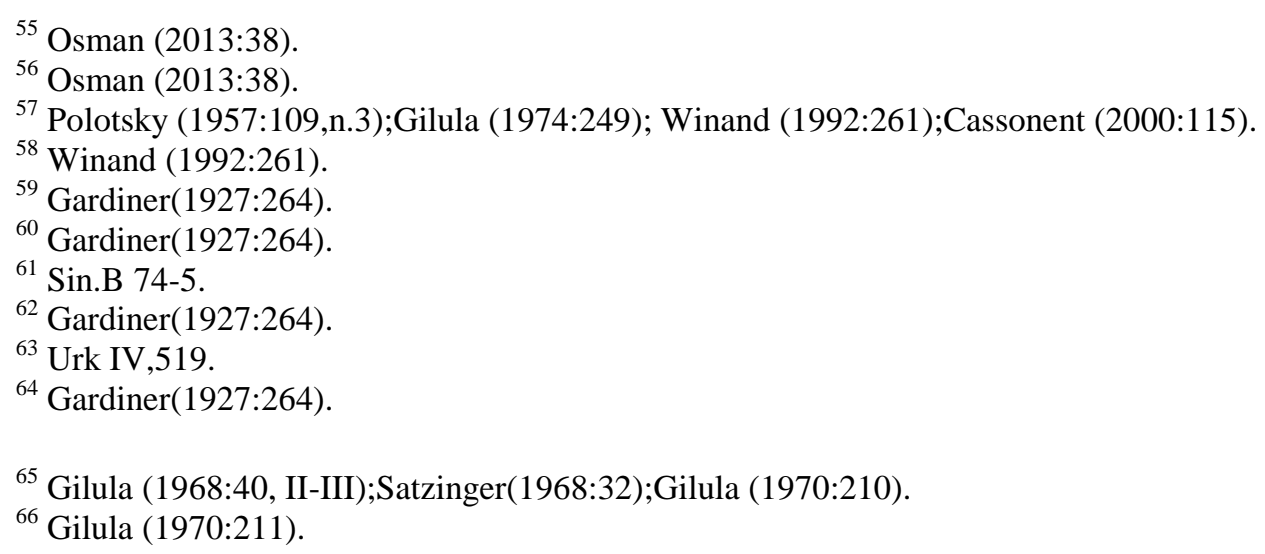


In truth - and not as what is said by duty in the Necropolis, I did it all.

Ex (2):

Mo'alla v 22 (inscr.13). ${ }^{67}$

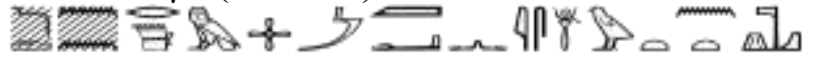

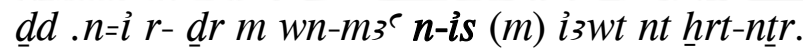

I did it in truth, not as a duty of the Necropolis.

In these two examples there are two emphatic sentences with adverbial adjuncts $i r . n=i$ ' $n d \underline{d} d$. $n=i$. In both of them there are more adverbials - as in the first example $m w n$ - $m^{2}, n$-is $m n w d d m i z w t$ but one is negated by $n$-is: $n$-is $m n w d d m i 3 w t$. In the second example also there are two adverbial

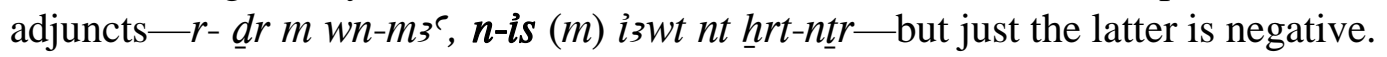

Note the verb itself is not negated in this type of sentence.

$\operatorname{Ex}(3)$
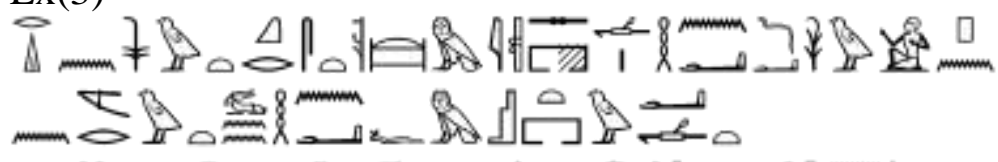

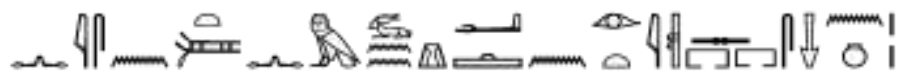

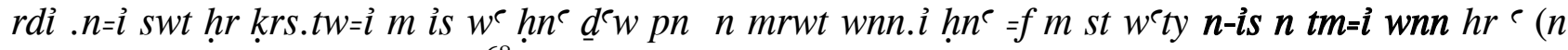
tm wnn hr ${ }^{\circ}=\dot{i}$ ) $n$ irt iswy snw. ${ }^{68}$

I caused myself to be buried in one tomb together with this Daw for the sake of being with him in one place, and not through the non-existence of the wherewithal to make two tombs. ${ }^{69}$

This example contains a "that-form" as a subordinate clause after $\mathrm{n}(\boldsymbol{n} \boldsymbol{t m}=\boldsymbol{i} \mathbf{w n n} \mathrm{hr}$ ) and is negated by $t m$. This adverbial phrase is the adverbial adjunct for rdi $. n=i$, and it as a whole is negated by $n$-is. ${ }^{70}$

Ex (4):

Pap.Carlsberg VI, $4^{71}$

A

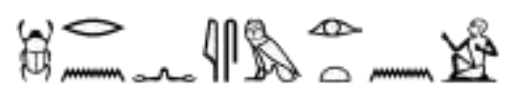

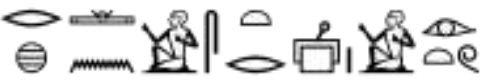

$m k$ sp hsi hpr $m$ h3w=i ...hpr .n n-ìs $m$ irt .n=i rh .n=i st $r$-sz ir.tw

An unfortunate incident happened in my time, and it wasn't by what I had done that it happened, only afterwards that I knew of it.

In this example, the negative adjunct is $n$-is $m$ irt $. n=i$.

\section{Results}

1- The second tense is equal to (Restriction form by innama) in Arabic

2- One can assume the Definition of the second tense " is one of the rhetorical feature in the ancient Egyptian Language, its importance attributed to its usage to attract attention to a special part of the sentence and put the focus on, the second tense is the syntactic shape of

\footnotetext{
${ }^{67}$ Gilula (1970:211).

${ }^{68}$ Urk I ,146-7.

${ }^{69}$ Gilula (1970:211).

${ }^{70}$ Gilula(1970:211).

${ }^{71}$ Cited by Gilula (1970:211).
} 
the Emphatic form and one can say that the restriction form is the correct counterpart of the second tense form.

3- The Second Tense form can be negated in three ways:

- $\quad$ By using the negative particle $n$........ is

- By using the negative verb " $t m "$

- $\quad$ By using the negative particle $n$-is

\section{Discussion}

There are at least three ways that a second tense or emphatic sentence can be negated. (1) If the verb itself is negated, the negative verb $\mathrm{tm}$ is used, which is the negation of the nominal forms of the verb (infinitive, participles and $s \underline{d} \underline{\underline{a}} t y . f y$, relative forms, as well as nominal $s \underline{d m} . f$ and rarely

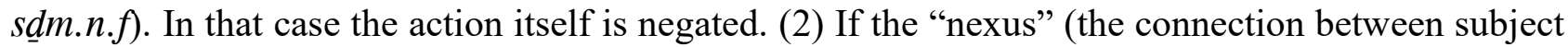
and predicate as explained by Gilula) is negated - or, according to A. Loprieno, if the "focus" (the adverbial as the pragmatic focus of the sentence) is negated, the two-part construction $n \ldots$ is is used. An example of this type would be the statement in Senwosret III's Year 16 stela, "he is not my son, $n$ ms.t(w).f is $n . i$ "it is not to me that he has been born." Note, the verb itself is not negated, although some English translations can make it seem as if it is. (3) If there are two or more adverbials, but only one is negated, then the negated adverbial is preceded by $n$ is. Again, the verb itself is not negated in this type of sentence.

Finally,One must know that there is a propensity to reject the "nominalization" in Polotsky's theory or to think that the so-called "Second Tense" is no more than a signal to focus the stressed adverbial adjunct, and must deal cautiously with the Standard Theory because it contains many grammatical errors which have been discussed by later scholars within new trends in earlier Egyptian grammar.

\section{Abbreviation}

CT De Buck, A., "The Egyptian Coffin Texts", 7 Vols., (Chicago 1935-1961)

KRI K. Kitchen, Ramesside Inscriptions, Historical and Biographical

Wb ERMAN A., GRAPOW .H., Wörterbuch der Agyptischen Sprache, 7 vols, (Leipzig, Berlin 1971).

West Papyrus Westcar.

ZÄS Zeitschrift für Ägyptische Sprache und Altertumskunde,( Leipzig-Berlin 1863).

\section{Bibliography}

Allen, J.P., (2014). Middle Egyptian: An Introduction to The Language and Culture of Hieroglyphs (3rd ed). Cambridge.

Allen, J.P., (2015). Middle Egyptian Literature: Eight Literary works of the Middle Kingdom, Cambridge.

Allen, J.P., (2015). A grammar of the Ancient Egyptian Pyramid Texts, (1), "Unis", Indiana, Eisenbrauns.

Bowling, A. C., (1962). Syntactical Examination of Clause function in Late - Egyptian Narrative, Ph. D. Dissertation, Brandeis University.

Cassonnet, P., (2000). Études de syntaxe néo-égyptian: Les temps seconds " i.sDm.f " et i-iri.f sDm", Entre syntaxe et semantique, Paris.

Collier, M., (2016). Alternatives and the grammar of Earlier Egyptian: Negation with Low-End Indefinite and Negation with n...is, Coping with Obscurity: The Brown Workshop on Earlier Egyptian Grammar, Atlanta, 151-168.

Englund, G., (1995), Middle Egyptian: An Introduction, (2nd ed). Uppsala. 
International Journal of Heritage, Tourism and Hospitality Vol. (12), No. (3/2)

Special issue on papers of the $11^{\text {th }}$ ICTH (2018) organized by Faculty of Tourism and Hotels,

Fayoum University

Gardiner,A., (1927). Egyptian Grammar: being an introduction to the study of hieroglyphs, Oxford (Clarendon press).

Gardiner, A., (1947). "H.J. Polotsky, Études de syntaxe copte, Review", JEA 33, 95-101.

Gilula, M., (1968). Enclitic particles in Middle Egyptian (in Hebrew), Ph.D Dissertation, Hebrew University.

Gilula, M., (1970). Review to (Satzinger, H., Die negativen Konstruktionen im AltMittelägyptischen, MÄs 12), JEA 56,205-214.

Gilula, M., (1972). Enclitic particles in Middle Egyptian, GM 2, 53-59.

Gilula, M., (1974). A tm.n.f sDm sentence ?, JEA 60,pp 249-250.

Hoch, J.E., (1997). Middle Egyptian Grammar, Mississauga (Benben Publication).

Jenni, H., (2010). Lehrbuch der klassisch-ägyptischen Sprache, Basel.

Meltzer, E., (1975). A rare use of Ds + suffix pronoun in Middle Egyptian, JARCE 12, 33-35.

Osman, O., (2013). The Verbal Forms in the Historical Texts of the Nineteenth Dynasty "An analytical study of the royal and non- royal direct speech," Ph.D Dissertation, Sohag.

Polotsky, H., (1957). The "Emphatic" sDm.n=f form, RdE 11, 109-117.

Satzinger, H., (1986). "On Tense and Aspect in Middle Egyptian," Crossroads, Chaos or the Beginning of a New Paradigm, Papers from the Conference on Egyptian Grammar, Helsingor 28-30 May, Kopenhagen (The Carsten Niebuhr Institute), 297-314.

Uljas, S., (2007). The Modal System of Earlier Egyptian Complement Clauses: A study in Pragmatics in a Dead Language, Leiden. Boston.

Winand, J., (1992). Etudes de neo- Egyptian, 1 La morphology verbale, Aegyptica Leodiensia 2, Liége.

Widmer, G., (1999). Emphasizing and Non-Emphasizing Second Tenses in the "Myth of Sun's Eye", JEA85, 165-188.

Winand, J., (1997). La Negation bn...iwnA Neo-Egyptien, LingAeg 5, 223-236. 